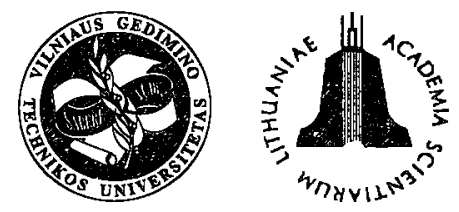

ISSN 1648-4142 TRANSPORT

http:/www.vtu.lt/english/editions

TRANSPORT - 2003, Vol XVIII, No 3, 120-123

\title{
CARGO FLOW AND TRANSIT IMPACTS ON PORT DEVELOPMENT
}

\author{
Vytautas Paulauskas, Valdas Lukauskas \\ Klaipèda University (KU), Bijūnu g. 17,LT-5800 Klaipèda, Lithuania.E-mail: laivyba@jtf.ku.lt \\ Received 200211 10, accepted 20030430
}

\begin{abstract}
The article analyses the changes of cargo flow structures, the distribution by overseas regions and their potential impact on port development. The analysis on how the cargo type and transit regions influence on the vessel capacity has been carried out. A view on the general range of ship size employed on the Baltic is given. The potential of the Klaipeda seaport is approached in respect of certain cargo flow evaluation. The tendencies of changing the main cargo flows through the Klaipeda seaport and the way they influence on ship sizes are researched. Possible influence of large-sized ship traffic on the port operations and development has been considered.
\end{abstract}

Keywords: port; cargo flow; transit; ships; port development; port technology.

\section{Introduction}

The cargo traffic and transit through ports are generally affected by multiple factors such as: geographical, macro economical, political, competition, technical, organizational etc. These factors along with the transit market situation are subject to continuous changes, like: -cargo flows are changing, some decline, while new ones are formed;

-new transport corridors are introduced, existing terminals are renovated and new terminals are built;

-changing requirements for transport corridors;

-ships selection and optimal ship exploitation;

-shipping lines optimization.

In order to maintain a transit port status the overall port development must be coordinated with the above processes.

The cargo flow is the essential factor of the proper functioning of a transport scheme, therefore the locations of cargo flow formation and destination, as well as cargo volume are considered the key objects in port development research. When cargo flows and transit operations are concerned, normally a primary attention is focused on the hinterland [1]. Cargo dispatch and destination overseas have been given a scant attention. Both Lithuanian and international research work considers the cargo flow-to-terminal parameter interaction ratios in liner service operations on a broader scale [2-4]. The parameters of vessels entering port utterly depend on cargo type and delivery distances, which in their turn will naturally influence on the parameters of accommodating ports and terminals [5-6]. Cargo transit research methods applied in development studies of Hamburg-
LeHavre range [7-8] and other ports. Different conditions existing in other regions make it impossible to implement these methods overall.

\section{Evaluation of Cargo Flow Changes}

In cargo transportation analysis all participants involved in a transport chain are of equally great importance. Whereas a decisive part in a cargo, as certain goods, circulation is assigned to the end customer (the consignee). The destination therefore determines the location and term of shipment, as well as the type of a vessel.

Hinterland situation in this respect of analysis is more favorable. Firstly, we have more information here available. Besides, both production and consumption potential cannot change rapidly. Thus the situation is much easier to forecast and analyze.

Overseas situation (in respect to the researched area) may change drastically very fast. Due to certain trade restrictions, price fluctuation on markets, trade with a certain region may unexpectedly decline and undermine all the previously existing forecasts.

While investigating the change of a particular cargo flow, it must be marked not just as absolute measure, but also in relation to all other ports of the range:

$$
\Delta Q_{i j}=k^{t+x} Q_{i j}^{t}+k_{i}^{t+x} Q_{i j}^{t}+\Delta q_{i j},
$$

where: $\Delta Q_{i j}$-an absolute change of cargo type $i$ at port $j$

$$
\Delta Q_{i j}=Q_{i j}^{t+x}-Q_{i j}^{t}
$$


where: $Q_{i j}^{t+x}$ - type $i$ cargo flow at port $j$ at the time moment $t+x$;

$Q_{i j}^{t}-$ type $i$ cargo flow at port $j$ at the initial moment of time $t$;

$k^{t+x}$ - coefficient of total cargo turnover change in the port range:

$$
k^{t+x}=\frac{\sum_{j=1}^{n} Q_{j}^{t+x}}{\sum_{j=1}^{n} Q_{j}^{t}},
$$

where: $Q_{j}^{t+x}$ - total cargo turnover at port $j$ at the time moment $t+x$;

$Q_{j}^{t}$ - total cargo turnover at port $j$ at the time moment $t$ $n$ - number of ports within the analyzed range.

$k_{i}^{t+x}$ - type $i$ cargo turnover change coefficient in all the port range:

$$
k_{i}^{t+x}=\frac{\sum_{j=1}^{n} Q_{i j}^{t+x}}{\sum_{j=1}^{n} Q_{i j}^{t},}
$$

$\Delta q_{i j}$ - relative change of cargo $i$ at port $j$.

Therefore the change of a particular cargo transit at port $j$ can be divided into three constituents as below:

- change caused by general and other cargo turnover change in the region;

- change caused by cargo structural changes in the region;

- relative cargo change within the port.

A positive relative change shows the transit increase in more than average within the region. A negative relative change (even at a positive absolute change result) shows the transit flow increase by less than average in the region, or decrease more than average in the region, i.e. a certain port has weakened its position in respect to cargo flow $i$ in the region.

Cargo flow changes in the port range are related to the changes in ship sizes and the changes of technical characteristics of the ports. It means, if cargo flow is increasing, then ships capable of carrying that cargo flow, along with the changes in ports must be evaluated.

In case a ship is sailing via few ports, the cargo amounts that can be delivered by the ship or ships capacity between ports can be calculated as follows:

$$
Q_{s}^{\prime}=Q_{s} \gamma
$$

where $Q_{s}-$ full ship capacity; $\gamma$ - ship capacity utilization coefficient.

If a ship operates on the port range, the cargo amount on board is changing during a voyage, and total cargo that can be delivered by one ship during entire voyage will be:

$$
Q_{s(f)}=Q_{s} \gamma \eta
$$

where $\eta$-cargo change coefficient during ship voyage, which can be equal to $k^{t+x}$ or $k_{i}^{t+x}$.

This situation could be very important if Baltic ports which will be included in the port chain, and cargo that is taken on board, such as containers in transcontinental transportation, general cargo in continental transportation and so on will be dispersed among European ports.

At the same time ports must be ready for such changes in a transportation process. That means that Eastern Baltic Ports should be able to work with new types of ships.

In fact, in the nearest future such possibility could appear for container transportation, because in some ports, e.g. Klaipeda, container terminals are not facilitated to work with big container vessels (4 and 5-th generations). So it is very important to have clearly defined perspectives of the possibilities to operate within a port range.

In this case port operators must know on what ship utilization level big container ships can call the range of ports and a particular port. Ship utilization efficiency during a voyage can be calculated as below:

$$
W_{s(f)}=\frac{Q_{s(f)} \eta_{s}}{t_{s}+\sum t_{p}+t_{r}},
$$

where: $t_{s}$ - ship sailing time on the voyage;

$\sum t_{p}$ - ship total time at ports; $t_{r}$-reserve time.

In any port of the range the ship can take a part of the cargo. In this case ship utilization efficiency in a particular port of the range will be:

$$
W_{s i}=\frac{Q_{i} \gamma \eta_{s}}{t_{s(i)}+\sum t_{p}+t_{r i}},
$$

where: $Q_{i}$ - cargo quantity in a particular port; $t_{s(i)}$ sailing time between two ports in range; $t_{p}$ - ship stay time in a particular port; $t_{r i}$-extra time necessary in a particular port (delay time).

As it is customary with container lines, a ship can enter a port of range if her utilization efficiency is bigger than 0,15 .

Based on the cargo flows or ship planning, an average minimum of cargo quantity could be arranged in the port that ships can enter, and at the same time the port technical characteristics that can meet the requirements from the ship side, that means $Q_{i}$ and $t_{p}$.

\section{Analysis of the Vessels to be Used on the Baltic}

Vessels operating on the Baltic, range widely in size 
from BALTMAX to small deadweight. The division presented here is utterly relative and made taking into consideration the actual operation possibilities within certain regions, as well as loading and docking facilities for the ships at certain terminals.

The majority of the Eastern Baltic ports are currently undergoing extensive reconstructions in order to be able to accommodate PANAMAX and bigger vessels, so that a direct link could be established bypassing the Western European ports.

Vessel sizes operated on the Baltic

\begin{tabular}{|l|c|c|}
\hline & $\begin{array}{c}\text { Draught, } \\
\mathrm{m}\end{array}$ & $\begin{array}{c}\text { Cargo } \\
\text { capacity, } \\
\mathrm{t}\end{array}$ \\
\hline $\begin{array}{l}\text { BALTMAX - largest ships capable to } \\
\text { operate on the Baltic }\end{array}$ & $13-17$ & $\begin{array}{c}100000- \\
150000\end{array}$ \\
\hline $\begin{array}{l}\text { PANAMAX - largest ships capable to } \\
\text { pass the Panama Canal }\end{array}$ & $11-12,5$ & $\begin{array}{c}50000- \\
70000\end{array}$ \\
\hline $\begin{array}{l}\text { Big ships - ships capable of entering } \\
\text { most of the Baltic ports, to be } \\
\text { accommodated only at some terminals }\end{array}$ & $9-11$ & $\begin{array}{c}20000- \\
30000\end{array}$ \\
\hline $\begin{array}{l}\text { Medium ships - ships operating on all } \\
\text { Baltic ports, accommodated actually at } \\
\text { any terminal. }\end{array}$ & $6-9$ & $8000-$ \\
\hline $\begin{array}{l}\text { Small ships - small ships to carry } \\
\text { minor cargoes }\end{array}$ & Under 6 & $\begin{array}{c}\text { Under } \\
6000\end{array}$ \\
\hline
\end{tabular}

Presently no accurate survey of vessel sizes in relation to particular types of cargo has been carried out. Given the cost of cargo, consignment volumes and delivery regions, we can maintain that the bigger the distance and cheaper the cargo, the bigger come optimum parameters of the ship (Table).

\begin{tabular}{|c|c|c|c|c|c|c|c|c|c|}
\hline BALTMAX & yxty & 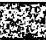 & & & & & & & \\
\hline PANAMAX & & x & & 4 & the & W & & & \\
\hline Big ship & & & & & 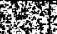 & 9 & 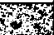 & 3 & \\
\hline Medium ships & & & & & & & 4 & $x$ & 4 \\
\hline Small ships & & & & & & & & 25 & tis \\
\hline & $\overline{0}$ & ర్ & 疋 & 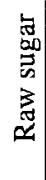 & $\begin{array}{c}\frac{n}{0} \\
\bar{z} \\
0 \\
0 \\
\overline{0} \\
\overline{0}\end{array}$ & $\begin{array}{l}\text { 焉 } \\
\sum\end{array}$ & 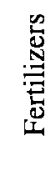 & 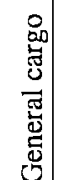 & 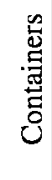 \\
\hline
\end{tabular}

Fig 1. Optimum Parameters of Vessels as per Different Type of Cargoes

Concerning the influence on the ship's size, the overseas cargo transit regions can be subdivided as follows:

-Baltic ports and nearest Nordic ports;

-Western European and Mediterranean ports (except the ports of Germany, Holland and Belgium);

-Distant ports (American, South Eastern Asian, African).

The ports of Germany, Belgium and Holland are grouped out to form a separate unit since here the majority of cargoes are re-loaded, especially in container flow.

\section{Analysis of Cargo Flow at the Klaipeda Seaport}

The main types of cargo groups: ro-ro, general cargo, oil products and fertilizers are clearly dominating at the Klaipeda seaport (Fig 1.). The flows of these goods are formed not only as transit. As a result of Lithuanian domestic industries and on this basis a part of this cargo, especially containers and a general cargo, the Klaipeda port has good possibilities of entry into ports range (Fig 2).

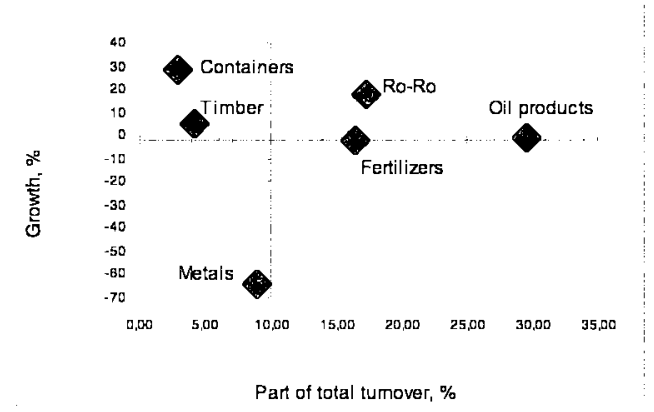

Fig 2. Analysis of Cargo Flow at the Klaipeda Seaport

As an example the traffic of fertilizer tends to increase to the European and Mediterranean ports, and direct shipping to the distant ports (Fig 3). Deliveries to the Baltic and Nordic ports generally decline. The part of Holland and Belgium remains of marginal stability. Thus fertilizer traffic analysis reveals an overall tendency for bigger ships, taking into account the accepting port facilities. The same is with other commodities.

In oil product traffic an increasing tendency for deliveries to Belgium and Holland dominates. These ports can facilitate and accommodate the biggest ships capable of sailing in the Baltic whereas the oil market demands enlarged-volume consignment so that to reduce the shipment costs. Thus oil traffic analysis shows a tendency for the use of bigger ships, considering the facilities available at the departure port (Fig 4).

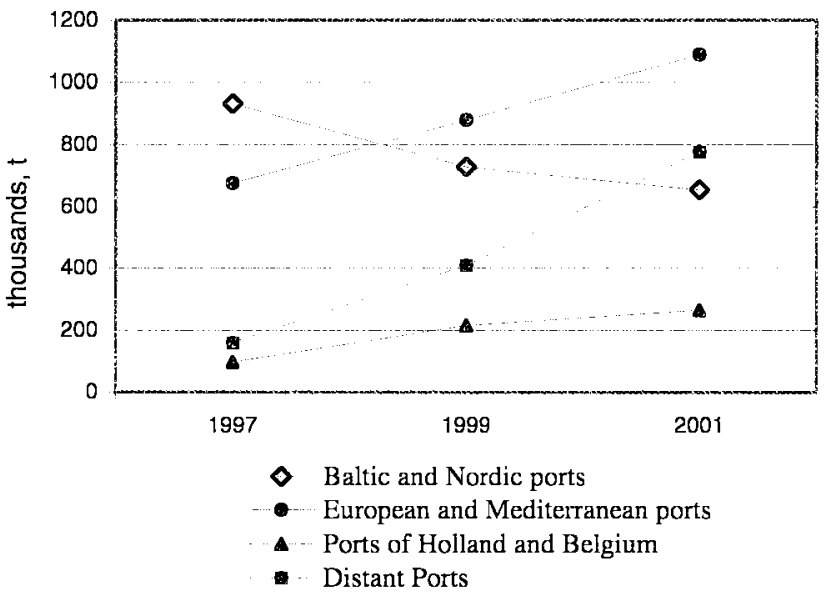

Fig 3. Fertilizer Traffic from the Klaipeda Seaport in Respect of Overseas Regions 


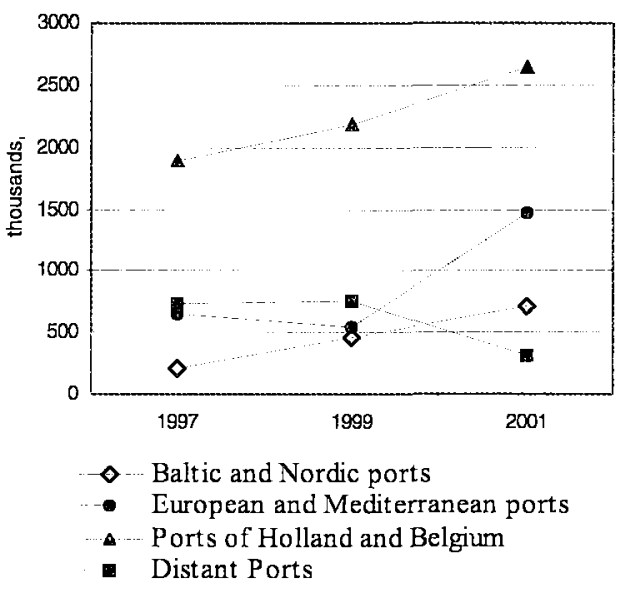

Fig 4. Oil Product Traffic from the Klaipeda Seaport in Respect of Overseas Regions

\section{Large-Tonnage Impact on the Port and Terminal Operations}

A large-sized vessel influences on the port operations in several aspects: technical, economical, ecological and organizational. Firstly, the port should have an adequate canal with a considerable amount of piers for bigger tonnages, sufficient storage capacity for a bigger number of cargoes to be accumulated, and employ advanced specialized technologies that demand significant investment in both port infrastructure and superstructure.

The use of large-sized vessels will likely reduce the traffic within the port. Subsequently, the probability of port accidents is reduced and ecologic factors are enhanced, as the fuel consumption per cargo unit of larger ships is lower.

Large-sized ships enable to produce cost-efficient and time-saving cargo operations, along with the optimum use of the pier - a greater ratio between the actual loading operation term and additional operations, like mooring, arrangement of ship and cargo formalities and these factors are very important for the liner ships, which work in shipping lines. Advanced terminal operation scheduling for big tonnages will lead to less technological and mobilization pauses, however general inconsistency of terminal operations may occur due to the increased demand of service facilities and personnel for servicing several ships at a time, or idle operation when there are no ships.

\section{Conclusions}

1. Cargo transit structure and operation areas generally determine the choice of tonnage used for shipment and ports/terminals capable to facilitate the ships.

2. Cargo transits on the Eastern Baltic in respect of overseas delivery regions and tonnages used have yet been little explored, basically due to the lack of available information and not enough ports ranges.

3. The analysis of the dominating cargo flow at the Klaipeda port shows a general tendency for the usage of bigger tonnages and possibilities of entry in shipping lines, which use port ranges.

4. Large tonnages used in ports have a positive influence on port operations, although it requires considerable initial investments and improved organization of work.

\section{References}

1. Brodin, A. Russian Transit in the Baltic Sea Region. Goteburg University, Center for European Research, 2002. $241 \mathrm{p}$.

2. Paulauskas, V. Optimal Ship Selection Principles in Linear Shipping. Transport Engineering (Transportas), 2000, Vol $X V$, No 2, p. $53-59$ (in Lithuanian).

3. Paulauskas, V.; Paulauskas, D.; Plačienè, B. The Analysis of Possibilities to Enter the Ports of the Baltic Sea for Big Container Ships. Transport, 2002, Vol XVII, No 2, p. 6670.

4. Mangan, J.; Lalwani, C. Modelling Port, Ferry Choice in RoRo Freight Transportation. International Journal of Transport Management, London. Elsevier Science, 2000, No 1, p. 15-28.

5. Baublys, A.; Petrauskas, B. Transport terminals (Transporto terminalai). Vilnius: Technika, 2002. 285 p. (in Lithuanian).

6. Paulauskas, V. Port Development. Kaipeda University Publisher House, 2000. 284 p. (in Lithuanian).

7. Haezendock, E. Essays on Strategy Analysis for Seaports. Leuven (Belgium): Garant Publisher, 2002. 228 p.

8. Huybrechts, M.; Meersman, Van Hooydonk; Verbeke, A.; Winkelmans, W. Port Competitiveness. Antwerp: Editions De Boeck Ltd, 2002. 151 p. 